
Revue canadienne de chimie

\title{
Fukushima-derived radioactivity measurements in Pacific salmon and soil samples collected in British Columbia, Canada
}

\begin{tabular}{|c|c|}
\hline Journal: & Canadian Journal of Chemistry \\
\hline Manuscript ID & cjc-2017-0272.R1 \\
\hline Manuscript Type: & Article \\
\hline Date Submitted by the Author: & 20-Jun-2017 \\
\hline Complete List of Authors: & $\begin{array}{l}\text { Domingo, Thomas; Simon Fraser University, Department of Chemistry } \\
\text { Starosta, Krzysztof; Simon Fraser University, Department of Chemistry } \\
\text { Chester, Aaron; Simon Fraser University, Department of Chemistry } \\
\text { Williams, Jonathan; Simon Fraser University, Department of Chemistry } \\
\text { Lehnert, Sarah; Fisheries and Oceans Canada Newfoundland and Labrador } \\
\text { Region, Northwest Atlantic Fisheries Centre } \\
\text { Gantner, Nikolaus; University of Northern British Columbia, Environmental } \\
\text { Science Program } \\
\text { Alava, Juan; University of British Columbia, Institute for the Oceans and } \\
\text { Fisheries; Vancouver Aquarium Marine Science Centre, Ocean Pollution } \\
\text { Research Program }\end{array}$ \\
\hline $\begin{array}{r}\text { Is the invited manuscript for } \\
\text { consideration in a Special } \\
\text { Issue?: }\end{array}$ & SFU \\
\hline Keyword: & $\begin{array}{l}\text { Fukushima, }<\text { sup }>134</ \text { sup }>\text { Cs, }<\text { sup }>137</ \text { sup }>\text { Cs, Pacific salmon and } \\
\text { soil, Low-background gamma-ray spectroscopy }\end{array}$ \\
\hline
\end{tabular}




\title{
Fukushima-derived radioactivity
} measurements in Pacific salmon and soil samples collected in British Columbia, Canada

Thomas Domingo, Krzysztof Starosta, Aaron Chester, Jonathan Williams, Sarah J. Lehnert, Nikolaus Gantner, and Juan José Alava

\begin{abstract}
Despite the many studies which have shown minimal health risks to individuals living outside of Japan following the Fukushima Nuclear Accident, there are persisting concerns regarding the consumption of Pacific seafood which may be contaminated with radioactive species from Fukushima. To address these concerns, the activity concentrations of anthropogenic ${ }^{134} \mathrm{Cs}$ and ${ }^{137} \mathrm{Cs}$ as well as naturally occurring ${ }^{40} \mathrm{~K}$ were measured in Pacific salmon collected from Kilby Provincial Park, BC in 2013 and from the Quesnel River, BC in 2014 using low-background gamma-ray spectroscopy. In addition, soil samples and a single
\end{abstract}

Thomas Domingo, ${ }^{1}$ Krzysztof Starosta, ${ }^{2}$ Aaron Chester, and Jonathan Williams. Department of Chemsitry, Simon Fraser University, Burnaby, BC V5A 1S6, Canada

Sarah J. Lehnert. Northwest Atlantic Fisheries Centre, Fisheries and Oceans Canada, St. John's, NL A1C 5X1, Canada

Nikolaus Gantner. Environmental Science Program, University of Northern British Columbia, Prince George, BC V2N 4Z9, Canada

Juan José Alava. Institute for the Oceans and Fisheries, University of British Columbia, Vancouver, BC V6T 1Z4, Canada. Ocean Pollution Research Program, Vancouver Aquarium Marine Science Centre, Vancouver, BC V6B 3X8, Canada

${ }^{1}$ Corresponding author (e-mail: tdomingo@sfu.ca).

${ }^{2}$ Corresponding author (e-mail: starosta@sfu.ca). 
roof-debris sample were collected and analysed to provide a record of Fukushima-derived contamination in BC. Cesium-134 was not detected in the salmon samples. Cesium-137 was not detected in any of the sockeye or chum samples, though it was detected in all of the Chinook samples. The weighted average $( \pm 1 \sigma){ }^{137} \mathrm{Cs}$ activity concentration in the Chinook salmon collected in 2013 and 2014 was 0.23 (3) and $0.20(3) \mathrm{Bq} / \mathrm{kg}$ fresh weight respectively. A conservative annual dose estimate for an adult who consumes the average Canadian quantity of seafood per year, contaminated with radiocesium at the maximum concentrations measured in this campaign was calculated to be $0.054 \mu \mathrm{Sv}$ per year. Cesium134 was detected in all but two of the soil samples. A weak positive correlation was observed between presence of ${ }^{134} \mathrm{Cs}$ and of ${ }^{7} \mathrm{Be}$ suggesting the ${ }^{134} \mathrm{Cs}$ arrived via atmospheric deposition. Cesium-137 was present in every soil sample though the total radiocesium activity concentrations measured were significantly less than action levels set by Health Canada.

Key words: Fukushima, Pacific salmon, Dose estimate, Low-background gamma-ray spectroscopy, soil, ${ }^{134} \mathrm{Cs},{ }^{137} \mathrm{Cs},{ }^{7} \mathrm{Be}$.

\section{Introduction}

Following the Fukushima Nuclear Accident (FNA) in 2011, large quantities of fission fragments and nuclear fuel were released into the environment from the damaged Fukushima Dai-ichi Nuclear Power Plant. Two gamma-ray emitting fission fragments commonly used to track the fallout from nuclear accidents are ${ }^{134} \mathrm{Cs}\left(\mathrm{T}_{1 / 2}=2.06 \mathrm{y}\right)$ and ${ }^{137} \mathrm{Cs}\left(\mathrm{T}_{1 / 2}=30.17 \mathrm{y}\right)$. These cesium radioisotopes were released in large quantities from the Fukushima Dai-ichi discharge channels at a ${ }^{134} \mathrm{Cs} /{ }^{137} \mathrm{Cs}$ activity ratio of $0.99(3)$ [1] though this activity ratio will change over time due to the different halflives of each radioisotope.

Before the FNA, there was an existing population of ${ }^{137} \mathrm{Cs}$ throughout the environment due to its relatively long half-life as a legacy of atmospheric nuclear weapons testing which stopped in 1980 and the Chernobyl Nuclear Accident which occurred in 1986. The ${ }^{134} \mathrm{Cs}$ released from these events would have entirely decayed away prior to the FNA making detection of ${ }^{134} \mathrm{Cs}$ an unambiguous indicator of Fukushima-derived contamination. Despite the previous worldwide contamination of ${ }^{137} \mathrm{Cs}$ before the FNA, there is no natural source of this cesium isotope in the environment. Therefore, if a preFukushima baseline of ${ }^{137} \mathrm{Cs}$ can be established, ${ }^{137} \mathrm{Cs}$ may still be used as a useful tracer with ${ }^{134} \mathrm{Cs}$ to monitor the spread of Fukushima-derived radionuclides.

In the years after the FNA, there have been significant efforts by the international community to measure the radionuclides from Fukushima which were released into the atmosphere [2-6] or directly into the Pacific Ocean $[1,7-9]$. As cesium has been previously shown to accumulate in tissues, addi- 
tional monitoring campaigns have been initiated to investigate the contamination of various freshwater $[5,6]$ and marine $[7,10-15]$ biota as well as to develop ${ }^{137} \mathrm{Cs}$ bioaccumulation models in Pacific food-webs [16].

The primary purpose of many radionuclide monitoring campaigns is to describe the degree of contamination in the environment or to provide a dose estimate to the public within a specific region. The data from these campaigns may then be pooled together to provide global estimates for the total worldwide radionuclide contamination from all major nuclear events [8] or to provide detailed effective dose estimates for the global population [17].

Though none of the monitoring campaigns listed above measured total radiocesium $\left({ }^{134} \mathrm{Cs}+{ }^{137} \mathrm{Cs}\right)$ activity concentrations near Health Canada's action levels for total radiocesium at $1000 \mathrm{~Bq} / \mathrm{kg}$ [18] or effective doses near the dose limit set by the Canadian Nuclear Safety Commission (CNSC) at $1 \mathrm{mSv} / \mathrm{y}$ [19], there are still concerns held by many in the general public regarding the safety of consuming Pacific seafood. The primary objective of the current study was to address these concerns by monitoring radiocesium activity concentrations in various species of Pacific salmon, anadromous fish which have been seen to accumulate and transport pollutants across the Pacific Ocean to their spawning locations $[20,21]$.

To accomplish this task, Pacific salmon collected in 2013 and 2014 from two locations of the Fraser River watershed were measured to quantify their level of Fukushima-derived contamination using low-background gamma-ray spectroscopy at Simon Fraser University. To provide a simple reference, the naturally occurring radioactive material (NORM) isotope ${ }^{40} \mathrm{~K}$ was also measured in each salmon sample. The activity concentrations as well as the dose contributions from anthropogenic and NORM sources in each sample were compared. As there was no alpha spectrometer available to measure ${ }^{210} \mathrm{Po}$, the NORM isotope responsible for the largest dose to individuals, ${ }^{210}$ Po data from Ref. [13] was used in the comparison.

The second objective of the monitoring campaigns was to provide a record of anthropogenic contamination in Pacific salmon and soil samples collected in BC. Purely out of curiosity, soil samples and a roof-debris sample were collected at various locations across BC to investigate if there was significant atmospheric deposition of radionuclides from Fukushima. To verify that the anthropogenic radionuclides detected were delivered via atmospheric deposition, cosmogenic ${ }^{7} \mathrm{Be}$, a NORM isotope continuously produced in the atmosphere, was measured as well. The results of the salmon and soil/debris monitoring campaigns are reported below.

(c)2017 NRC Canada 


\section{Methods}

\subsection{Salmon collection and processing}

Fig. 1. A map of British Columbia, Canada with the various sample collection sites labelled. The inset in the upper-left corner shows the location of British Columbia shaded within Canada. Black stars indicate where soil or roof-debris samples were collected and grey boxes indicate where Pacific salmon samples were collected. The region from Vancouver to Harrison Mills is expanded upon in the upper-right inset to more clearly show the sample collection sites. The details for which specific sample(s) were collected from each sampling location is described in Sections 2.1 and 2.2.

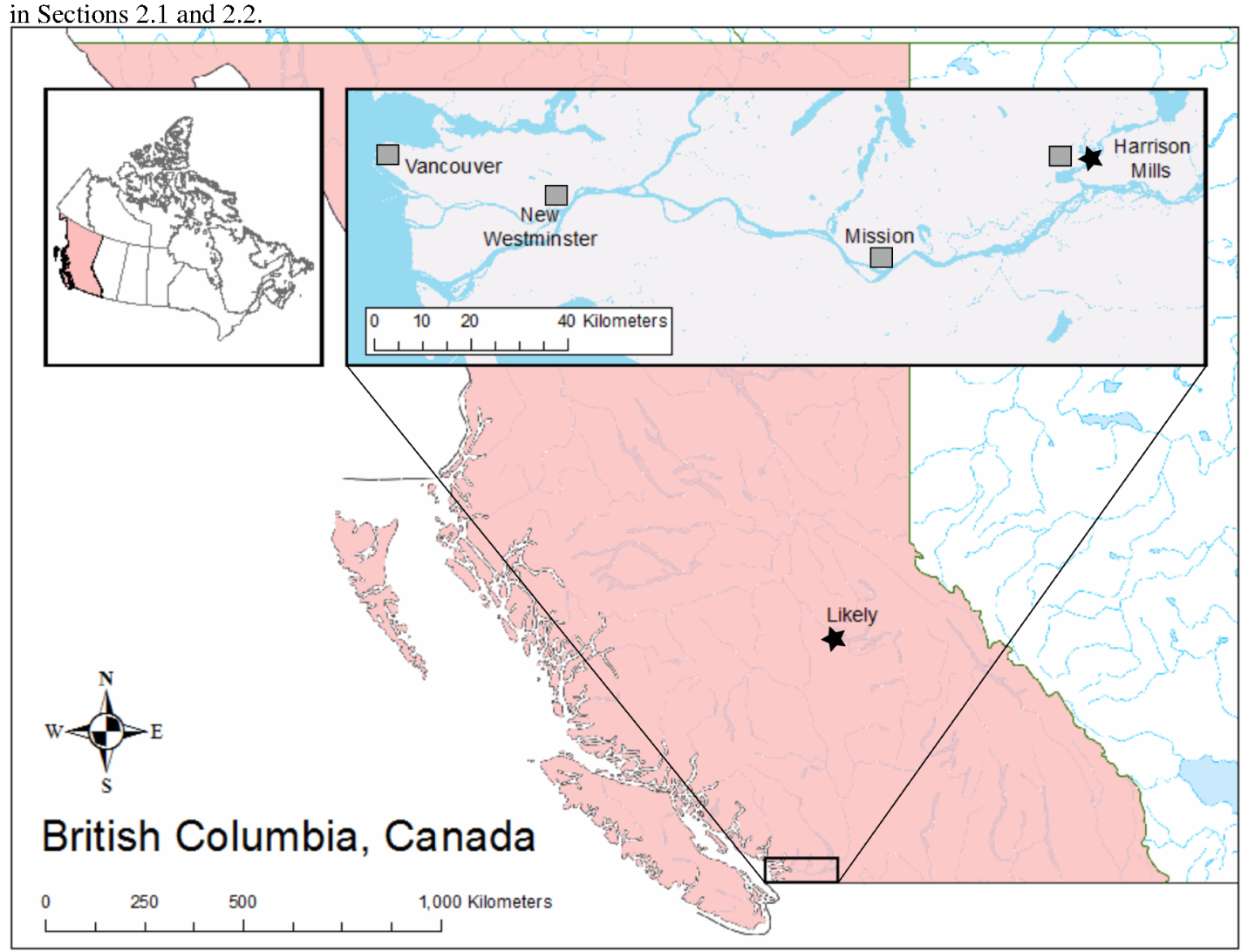

Three sockeye (Oncorhynchus nerka), three chum (O. keta), and three Chinook (O. tshawytscha) salmon samples were collected on November 16, 2013 from their spawning site in Harrison River, Kilby Provincial Park, BC. An additional four Chinook samples were collected on the way to their spawning grounds from the Quesnel River near Likely, BC on October 6, 2014. These sampling locations are labelled in Fig. 1 as grey squares. The fillet from each salmon was freeze-dried and homogenised to reduce its volume and to allow it to take the shape of the measurement vessel. The mass 
of each fillet was measured before and after processing.

\subsection{Soil collection and processing}

Soil samples were collected from various inland locations in British Columbia. Two topsoil samples were collected on March 21, 2014 from Queen's Park, New Westminster, BC. Four topsoil samples were collected on April 12, 2014 from the riparian forest by Harrison River in Kilby Provincial Park, BC. A single topsoil sample was collected on April 12, 2014 from a residential area in Mission, BC. A final roof-debris sample composed of pine needles and various plant debris was collected on June 5, 2014 from a residential roof in Vancouver, BC. Though this sample is technically not soil, it was processed and measured in the same manner as the soil samples and will be presented with them. These sampling locations are labelled in Fig. 1 as black stars. To reduce the volume and dehydrate each sample, each sample was baked in an oven at $400^{\circ} \mathrm{C}$ until it had a stable mass. The mass of each sample was measured before and after baking.

\subsection{Radionuclide detection}

The gamma-ray emitting radionuclides in each sample were detected with the Germanium detector for Elemental Analysis and Radioactivity Studies (GEARS) at the Simon Fraser University Nuclear Science Laboratory (SFU NSL). GEARS contains a p-type GEM profile series high-purity germanium (HPGe) coaxial detector with a crystal diameter and length of 59.0 and $74.4 \mathrm{~mm}$ respectively. This detector has proven useful in the past to monitor ${ }^{131}$ I levels in environmental samples in the months immediately following the nuclear accident [2] and more recently in a similar project to measure radiocesium in sockeye salmon collected from First Nations fisheries on Vancouver Island [15]. A more detailed description of the detector setup for the environmental monitoring campaigns may be read in Ref. [2]. The absolute efficiency of GEARS while measuring point sources was evaluated using the technique described in Ref. [22]. Homogenised environmental samples were measured for 2-10 days in a glass vial, a $300 \mathrm{~mL}$ Marinelli beaker, or a $600 \mathrm{~mL}$ Marinelli beaker depending on their size. The absolute efficiency of GEARS while measuring environmental samples in these extended volumes was determined using the GEANT4 software package [23, 24] via the method described in Ref. [2].

\subsection{Radionuclide analysis}

In each measured spectrum, gamma-ray energy peaks were analysed with the gf 3 program in the RadWare software package [25]. Anthropogenic ${ }^{137} \mathrm{Cs}$ and NORM ${ }^{40} \mathrm{~K}$ and ${ }^{7} \mathrm{Be}$ detection was confirmed and quantified via the presence of a 661.7 , a 1460.8 , and a $477.6 \mathrm{keV}$ gamma-ray peak in the 
measured spectrum respectively. Detection of anthropogenic ${ }^{134} \mathrm{Cs}$ was confirmed via the presence of the two highest intensity ${ }^{134} \mathrm{Cs}$ gamma-ray peaks at 604.7 and $795.9 \mathrm{keV}$ though only the $604.7 \mathrm{keV}$ peak was used for quantification. The $795.9 \mathrm{keV}$ peak was only used to verify the presence of ${ }^{134} \mathrm{Cs}$ as there was a significant error when measuring the area of this energy peak. This error arose because the detection of this gamma-ray peak required deconvoluting it from a partially overlapping background peak from ${ }^{228} \mathrm{Ac}$, another NORM isotope. In the event where one of the radionuclides of interest could not be detected in a given sample, the maximum activity concentration of that radionuclide potentially present was determined by calculating the minimum detection limit (MDL) for that radionuclide via the method described in Ref. [26].

Measured activities were background corrected either with a three day long background measurement taken before the monitoring campaign if the sample was measured in the first batch or a ten day long background measurement taken in between sample measurements if the samples were measured in the second batch. Shorter background measurements were taken periodically to ensure there was no significant changes to the background over the duration of the entire monitoring campaign. The dry weight (dw) activity concentrations for radionuclides measured in each sample $\left[A_{\mathrm{dw}}\right]$ were determined via:

$\left[A_{\mathrm{dw}}\right]=\frac{A}{m_{\mathrm{dw}}}$,

where $A$ is the measured activity of the radionuclide and $m_{\mathrm{dw}}$ is the mass of the sample after it was processed/freeze-dried. The fresh weight (fw) activity concentrations of radionuclides present in each environmental sample $\left[A_{\mathrm{fw}}\right]$ was then calculated via:

$\left[A_{\mathrm{fw}}\right]=\left[A_{\mathrm{dw}}\right] \frac{m_{\mathrm{dw}}}{m_{\mathrm{fw}}}$,

where $m_{\mathrm{fw}}$ is the mass of the sample before it was processed/freeze-dried. The fw activity concentration for each measured radionuclide was then decay corrected to the date of sample collection using its halflife value reported by NNDC [27].

\section{Results}

The results of the radioactivity monitoring campaign in Pacific salmon are summarised in Tab. 1 and in soil are summarised in Tab. 2 .

(c)2017 NRC Canada 
Fig. 2. An example gamma-ray spectrum collected using GEARS to measure Pacific salmon sample: ChinookHR-9 (black) with a background spectrum (grey) overlaid on top. Both spectra are time scaled to represent a 100,000 second long measurement livetime. The measured spectrum ranges from $450 \mathrm{keV}$ to $1500 \mathrm{keV}$ to show that there is no peak at $478 \mathrm{keV}$ which would signify the presence of ${ }^{7} \mathrm{Be}$ in the sample as well as to show the dominating feature in this spectrum, the $1461 \mathrm{keV}$ peak which indicates the presence of the NORM isotope ${ }^{40} \mathrm{~K}$. The inset spectrum shows the region of interest where one would observe a $605 \mathrm{keV}$ peak if ${ }^{134} \mathrm{Cs}$ was present in the sample. The inset also allows the $662 \mathrm{keV}$ peak to be seen which implies ${ }^{137} \mathrm{Cs}$ contamination in the sample. This salmon sample had the largest ${ }^{137} \mathrm{Cs}$ activity concentration measured of all the Pacific salmon samples tested.

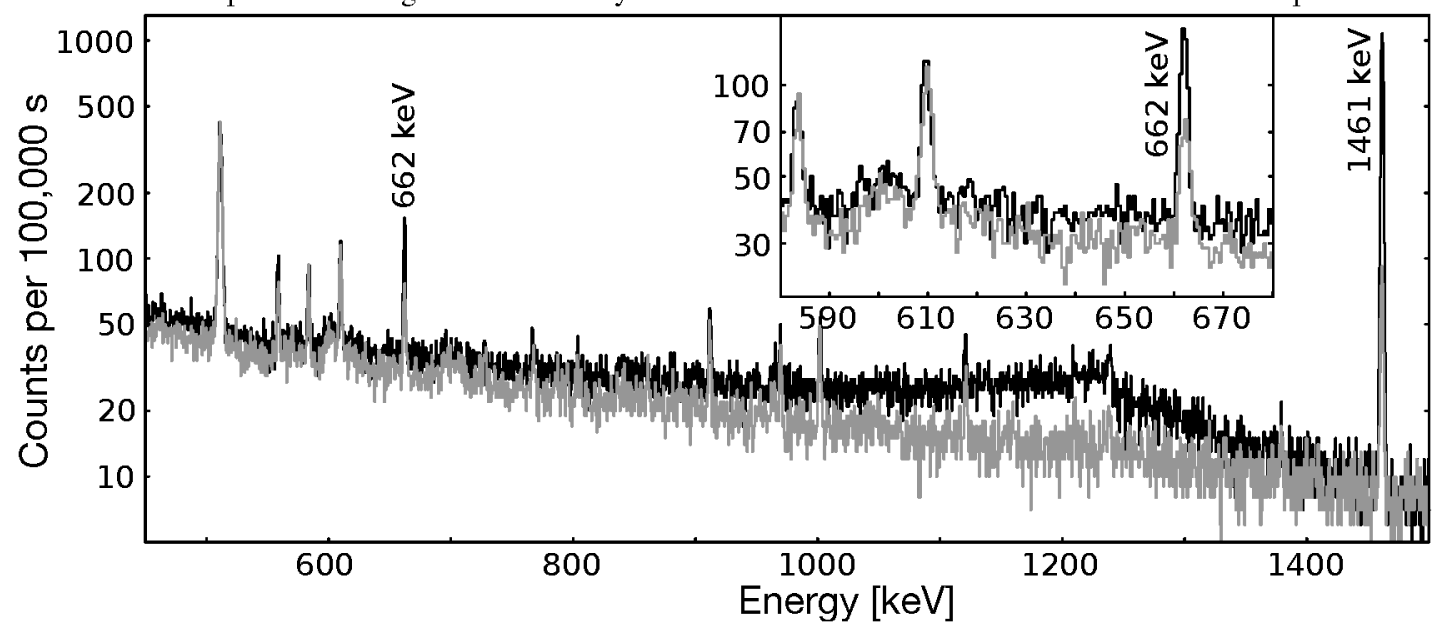

\subsection{Salmon analysis}

Presence of anthropogenic ${ }^{134} \mathrm{Cs}$ could not be confirmed in any of the salmon samples collected in 2013 or 2014 . The ${ }^{137} \mathrm{Cs}$ radionuclide however was detected in three of the nine salmon samples collected in 2013 with activity concentrations ranging from 0.10 to $0.36 \mathrm{~Bq} / \mathrm{kg}$ fw. As all three of the samples with positive detection of ${ }^{137} \mathrm{Cs}$ were Chinook salmon, only Chinook were collected in 2014. All of the 2014 Chinook salmon samples also contained measurable quantities of ${ }^{137} \mathrm{Cs}$ with activity concentrations ranging from 0.16 to $0.23 \mathrm{~Bq} / \mathrm{kg}$ fw. For comparison, the activity concentration of naturally occurring ${ }^{40} \mathrm{~K}$ in all of the salmon samples collected ranged from 75.6 to $128 \mathrm{~Bq} / \mathrm{kg} \mathrm{fw}$ with no major differences between salmon species. This is in contrast to the measured ${ }^{137} \mathrm{Cs}$ activities which differed significantly between the Chinook and other salmon species measured. Time delays in receiving the salmon samples at the SFU NSL resulted in a significant reduction of ${ }^{7} \mathrm{Be}$ activity in each sample. Therefore ${ }^{7}$ Be was not analysed in the salmon monitoring campaign. An example gamma-ray spectrum using the GEARS detector to measure a salmon sample may be viewed in Fig. 2 .

(c) 2017 NRC Canada 
Table 1. The activity concentrations for ${ }^{40} \mathrm{~K},{ }^{134} \mathrm{Cs}$, and ${ }^{137} \mathrm{Cs}$ measured in the three species of Pacific salmon tested are reported below. The top nine samples were collected on November 16, 2013 from the Harrison River, Kilby Provincial Park, BC while the bottom four were collected on October 6, 2014 from the Quesnel River by Likely, BC. The activity concentrations $( \pm 1 \sigma)$ listed below have been corrected for background and decay corrected to the sample collection date. When a radionuclide could not be detected, the minimum detection limit (MDL) was calculated via the method described in Ref. [26] to provide an upper limit for the activity concentration of that radionuclide in the sample. MDL values are presented following a less than " $<$ " symbol. ${ }^{\dagger} \mathrm{HR}=\mathrm{Harrison}$ $\underline{\text { River and QR = Quesnel River. }}$

\begin{tabular}{lccccc}
\hline \multirow{2}{*}{ Sample ID } & \multirow{2}{*}{ Collection } & Collection Date & \multicolumn{2}{c}{ Activity Concentration (Bq/kg fw) } \\
\cline { 5 - 6 } & Location $^{\dagger}$ & (YYYY-MM-DD) & ${ }^{40} \mathrm{~K}$ & ${ }^{134} \mathrm{Cs}$ & ${ }^{137} \mathrm{Cs}$ \\
\hline Sockeye-HR-1 & HR & $2013-11-16$ & $102.2(19)$ & $<0.09$ & $<0.08$ \\
Sockeye-HR-2 & HR & $2013-11-16$ & $123(2)$ & $<0.12$ & $<0.11$ \\
Sockeye-HR-3 & HR & $2013-11-16$ & $100.3(17)$ & $<0.07$ & $<0.06$ \\
Chum-HR-4 & HR & $2013-11-16$ & $95.8(15)$ & $<0.06$ & $<0.05$ \\
Chum-HR-5 & HR & $2013-11-16$ & $100(2)$ & $<0.13$ & $<0.11$ \\
Chum-HR-6 & HR & $2013-11-16$ & $75.6(15)$ & $<0.08$ & $<0.07$ \\
Chinook-HR-7 & HR & $2013-11-16$ & $110(2)$ & $<0.11$ & $0.19(6)$ \\
Chinook-HR-8 & HR & $2013-11-16$ & $101.3(19)$ & $<0.10$ & $0.10(6)$ \\
Chinook-HR-9 & HR & $2013-11-16$ & $110.0(19)$ & $<0.08$ & $0.36(5)$ \\
\hline Chinook-QR-70 & QR & $2014-10-06$ & $128(2)$ & $<0.16$ & $0.16(6)$ \\
Chinook-QR-71 & QR & $2014-10-06$ & $110.7(18)$ & $<0.13$ & $0.20(5)$ \\
Chinook-QR-75 & QR & $2014-10-06$ & $116.1(18)$ & $<0.14$ & $0.23(6)$ \\
Chinook-QR-77 & QR & $2014-10-06$ & $109.5(19)$ & $<0.15$ & $0.22(6)$ \\
\hline
\end{tabular}

\subsection{Soil analysis}

Presence of anthropogenic ${ }^{134} \mathrm{Cs}$ was confirmed in six out of the eight samples measured with activity concentrations ranging from 0.075 to $0.456 \mathrm{~Bq} / \mathrm{kg}$ fw. The ${ }^{137} \mathrm{Cs}$ radionuclide was detected in all eight samples with activity concentrations ranging from 1.60 to $13.80 \mathrm{~Bq} / \mathrm{kg}$ fw. For comparison, the activity concentration of naturally occurring ${ }^{40} \mathrm{~K}$ in all of the samples ranged from 12.9 to 152.7 $\mathrm{Bq} / \mathrm{kg}$ fw. The naturally occurring ${ }^{7} \mathrm{Be}$ radionuclide was detected in all of the samples with activity concentrations ranging from 0.7 to $74.8 \mathrm{~Bq} / \mathrm{kg}$ fw. Two example gamma-ray spectra using GEARS to measure the roof-debris sample which had the largest measured quantity of ${ }^{134} \mathrm{Cs}$ and soil sample 
Fig. 3. An example gamma-ray spectrum collected using GEARS to measure roof-debris sample: Debris-H1 (black) with a background spectrum (grey) overlaid on top. Both spectra are time scaled to represent a 100,000 second long measurement livetime. There is a strong peak at $478 \mathrm{keV}$ and a relatively weaker peak at $1461 \mathrm{keV}$ which signifies the presence of the NORM isotopes ${ }^{7} \mathrm{Be}$ and ${ }^{40} \mathrm{~K}$ respectively. The $662 \mathrm{keV}$ peak is also visible indicating the presence of anthropogenic ${ }^{137} \mathrm{Cs}$. The $796 \mathrm{keV}$ peak is enhanced which suggested the presence of ${ }^{134} \mathrm{Cs}$. Presence of ${ }^{134} \mathrm{Cs}$ is confirmed in the inset spectrum where one can clearly observe a peak at $605 \mathrm{keV}$. This sample had the largest ${ }^{134} \mathrm{Cs}$ activity concentration measured of all samples tested in the monitoring campaign.

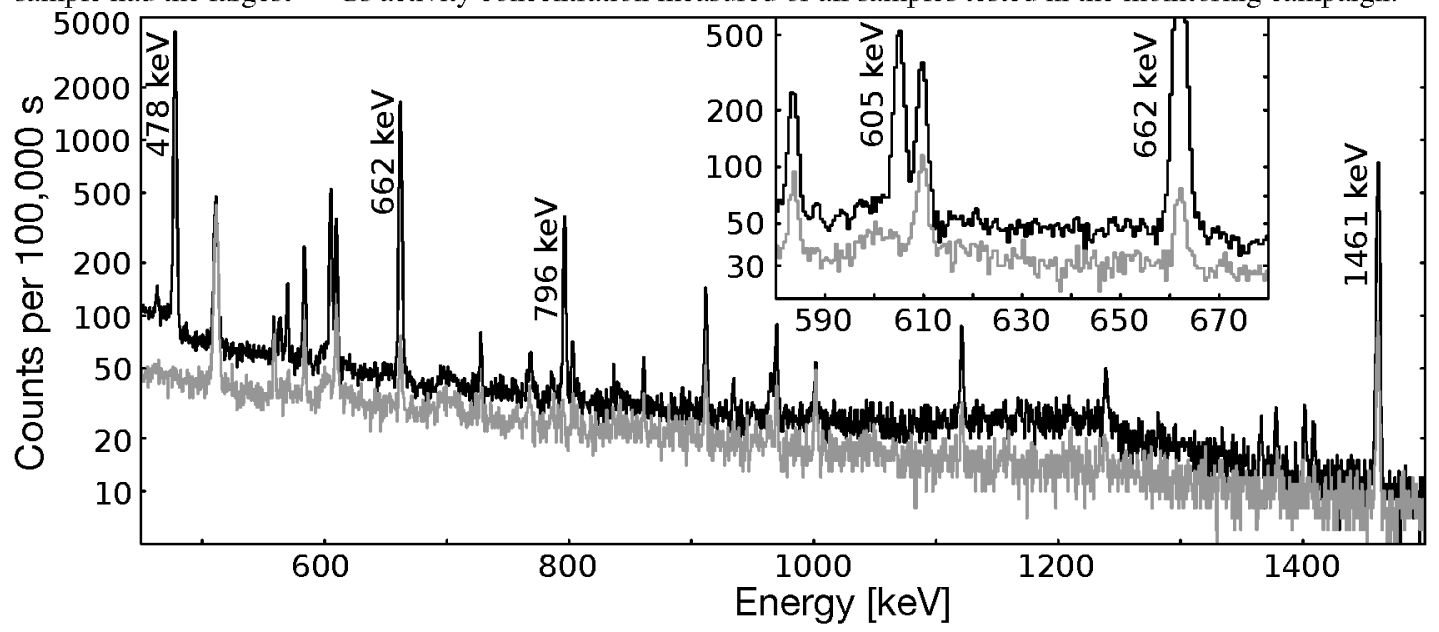

Soil-HR-S1 which had the largest measured quantity of ${ }^{137} \mathrm{Cs}$ of all the samples measured, may be viewed in Fig. 3 and Fig. 4 respectively.

\section{Discussion}

The environmental monitoring campaigns had two primary objectives. The first was to provide clear and concise information regarding the potential for negative health impacts to the public associated with consuming Pacific salmon potentially contaminated with anthropogenic, e.g. Fukushima-derived radionuclides. Previous studies have attempted to measured the ${ }^{134} \mathrm{Cs}$ and ${ }^{137} \mathrm{Cs}$ content in Pacific salmon $[13,14]$ though, when attempting to measure individual samples, high detection limits have been a limiting factor. A more recent study [15] analysing sockeye salmon collected from Alberni Inlet on the west coast of Vancouver Island, BC in June of 2014 did detect ${ }^{137} \mathrm{Cs}$ in five of the ten sockeye salmon sampled. The activity concentrations reported in this study are for the dry weight of each sample. Assuming these sockeye salmon had the average fresh weight to dry weight ratio the salmon samples dehydrated in the current study (5:1), the fresh weight activity concentrations of ${ }^{137} \mathrm{Cs}$ 
Fig. 4. An example gamma-ray spectrum collected using GEARS to measure soil sample: Soil-HR-S1 (black) with a background spectrum (grey) overlaid on top. Both spectra are time scaled to represent a 100,000 second long measurement livetime. There is a weak peak at $478 \mathrm{keV}$ and a peak at $1461 \mathrm{keV}$ which signifies the presence of the NORM isotopes ${ }^{7} \mathrm{Be}$ and ${ }^{40} \mathrm{~K}$ respectively. There is large peak at $662 \mathrm{keV}$ from anthropogenic ${ }^{137} \mathrm{Cs}$. The inset spectrum shows the region of interest where one observes a small $605 \mathrm{keV}$ peak indicating the presence of ${ }^{134} \mathrm{Cs}$ in the sample. This sample had the largest ${ }^{137} \mathrm{Cs}$ activity concentration measured of all samples tested in the monitoring campaign.

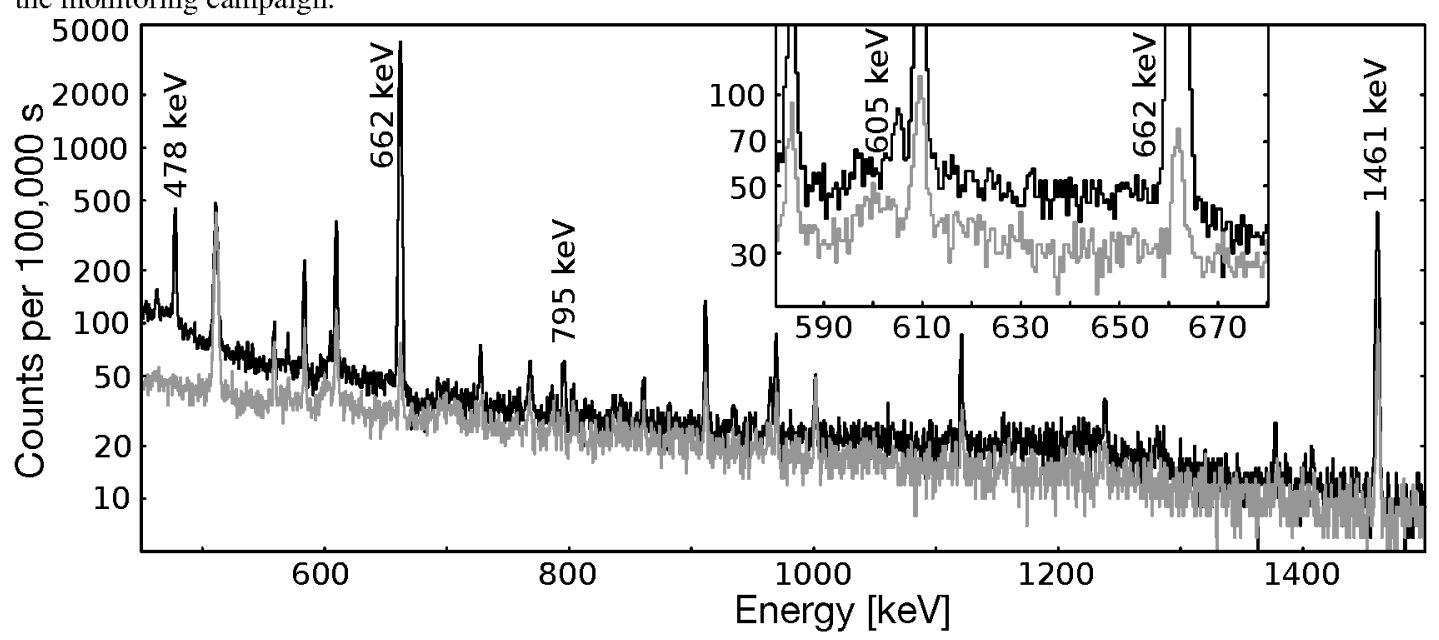

measured by Ref. [15] in sockeye salmon ranged from $0.05-0.28 \mathrm{~Bq} / \mathrm{kg}$ fw. One of the five sockeye also contained detectable quantities of ${ }^{134} \mathrm{Cs}$ which must be from the FNA. The average ${ }^{134} \mathrm{Cs}$ fw activty concentration measured in this sample assuming $80 \%$ moisture was $0.07 \mathrm{~Bq} / \mathrm{kg}$ fw. Despite detection of ${ }^{134} \mathrm{Cs}$ and ${ }^{137} \mathrm{Cs}$ in these sockeye salmon, the quantities measured in this study were not at concentrations which would pose any realistic health risk to an average Canadian seafood consumer.

Though none of the salmon measured in the current monitoring campaign contained detectable quantities of ${ }^{134} \mathrm{Cs}$ which would unambiguously indicate contamination of radionuclides originating from Fukushima, we can see in Table 1 that there were measurable levels of ${ }^{137} \mathrm{Cs}$ present in seven out of the thirteen salmon samples collected. As there was no signal from ${ }^{134} \mathrm{Cs}$ in these salmon, the ${ }^{137} \mathrm{Cs}$ measured is likely to be a legacy of atmospheric nuclear weapons testing or the Chernobyl Nuclear Accident and not from the FNA.

While the ${ }^{137} \mathrm{Cs}$ detected cannot be confirmed to originate from Fukushima, there is still a need to address the potential health impact of any anthropogenic radionuclides detected in the Pacific salmon monitoring campaign to assuage the intrinsic concern the majority of the public has toward radiation in 
Table 2. The activity concentrations for ${ }^{40} \mathrm{~K},{ }^{134} \mathrm{Cs},{ }^{137} \mathrm{Cs}$, and ${ }^{7} \mathrm{Be}$ measured in the soil/debris samples are reported below. The top two listed samples were collected from Queen's Park, New Westminster, BC, the following four from nearby Harrison River in Kilby Provincial Park, BC, the second to last from Mission, BC, and the final from a roof in Vancouver, BC. The activity concentrations $( \pm 1 \sigma)$ listed below have been corrected for background and decay corrected to the date of sample collection. When a radionuclide could not be detected, the minimum detection limit (MDL) was calculated via the method described in Ref. [26] to provide an upper limit for the activity concentration of the radionuclide in the sample. MDL values are presented following a less than " $<$ " symbol. ${ }^{\ddagger} \mathrm{QP}=$ Queen’s Park, KPP = Kilby Provincial Park, M = Mission, and V = Vancouver.

\begin{tabular}{lcccccc}
\hline \multirow{2}{*}{ Sample ID } & \multirow{2}{*}{ Collection } & Collection Date & \multicolumn{4}{c}{ Activity Concentration (Bq/kg fw) } \\
\cline { 4 - 7 } & Location $^{\ddagger}$ & (YYYY-MM-DD) & ${ }^{40} \mathrm{~K}$ & ${ }^{134} \mathrm{Cs}$ & ${ }^{137} \mathrm{Cs}$ & ${ }^{7} \mathrm{Be}$ \\
\hline Soil-QP-S4 & $\mathrm{QP}$ & $2014-03-21$ & $128.4(17)$ & $<0.04$ & $10.14(13)$ & $3.1(4)$ \\
Soil-QP-S5 & $\mathrm{QP}$ & $2014-03-21$ & $125.1(16)$ & $0.075(15)$ & $4.41(7)$ & $3.4(3)$ \\
Soil-HR-S1 & KPP & $2014-04-12$ & $17.9(5)$ & $0.109(14)$ & $12.25(15)$ & $7.8(3)$ \\
Soil-HR-S2 & $\mathrm{KPP}$ & $2014-04-12$ & $49.2(17)$ & $0.12(5)$ & $1.88(10)$ & $74.8(18)$ \\
Soil-HR-S3 & $\mathrm{KPP}$ & $2014-04-12$ & $34.3(7)$ & $0.069(12)$ & $1.60(4)$ & $25.4(4)$ \\
Soil-HR-S4 & $\mathrm{KPP}$ & $2014-04-12$ & $82.4(11)$ & $0.116(14)$ & $2.61(5)$ & $20.8(4)$ \\
Soil-M-01 & $\mathrm{M}$ & $2014-04-12$ & $152.7(20)$ & $<0.06$ & $13.80(17)$ & $0.7(3)$ \\
Debris-H1 & $\mathrm{V}$ & $2014-06-05$ & $12.9(3)$ & $0.456(8)$ & $1.82(3)$ & $34.5(4)$ \\
\hline
\end{tabular}

general. To address this concern, an upper limit for the dose contribution received by an individual from both anthropogenic and NORM isotopes measured in the salmon samples was calculated under two conditions. The first was for an individual who consumes $200 \mathrm{~g}$ salmon portion, representing a single meal, and the second was for an individual who consumes $8.8 \mathrm{~kg}$ of salmon over a year, the average Canadian rate of seafood consumption per year [28]. The dose upper limit was calculated assuming that all Pacific salmon consumed had the same level of anthropogenic contamination as sample ChinookHR-9, the sample which had the largest measured activity concentration of ${ }^{137} \mathrm{Cs}$. To make the upper limit very conservative, the activity concentration of ${ }^{134} \mathrm{Cs}$ was assumed to equal the MDL. Polonium210, a NORM which alpha-decays with a very low probability of gamma-ray emission, is responsible for the largest natural radioactive dose to individuals. Due to the low rate of gamma-emission, ${ }^{210} \mathrm{Po}$ in each sample could not be measured with GEARS. For the dose calculation, the average ${ }^{210}$ Po activity concentration in Chum salmon collected from the Canadian west coast measured by Ref. [13] was used in the dose calculation. To convert the activity concentrations in the salmon samples into effective 
doses received by individuals for the special case of consuming the salmon, dose coefficients from ICRP Publication 119 [29] were used. A breakdown for the conservative dose calculation is shown in Table 3.

Table 3. A breakdown of the upper limit for a dose received by an adult individual who consumes seafood with the same level of anthropogenic radionuclide contamination as sample Chinook-HR-9, the sample with the largest measured level of anthropogenic radionuclide contamination. The dose from a single $200 \mathrm{~g}$ meal as well as from average Canadian seafood consumption over a year $\left(8.8 \mathrm{~kg} / \mathrm{y}\right.$ [28]) are calculated for the anthropogenic $\left({ }^{134} \mathrm{Cs}\right.$ and $\left.{ }^{137} \mathrm{Cs}\right)$ and naturally occurring $\left({ }^{40} \mathrm{~K}\right.$ and $\left.{ }^{210} \mathrm{Po}\right)$ radioactive sources.

\begin{tabular}{lcccc}
\hline Radionuclide & $\begin{array}{c}\text { Activity Concentration } \\
(\mathrm{Bq} / \mathrm{kg} \mathrm{fw})\end{array}$ & $\begin{array}{c}\mathrm{DC}^{a} \\
(\mathrm{nSv} / \mathrm{Bq})\end{array}$ & $\begin{array}{c}\text { Dose (per meal) } \\
(\mathrm{nSv})\end{array}$ & $\begin{array}{c}\text { Dose (annual) } \\
(\mu \mathrm{Sv})\end{array}$ \\
\hline${ }^{134} \mathrm{Cs}$ & 19 & 0.31 & 0.014 \\
${ }^{137} \mathrm{Cs}$ & 0.08 & 13 & 0.92 & 0.041 \\
${ }^{40} \mathrm{~K}$ & $0.36(5)$ & 6.2 & 136 & 6.0 \\
${ }^{210} \mathrm{Po}$ & $110.0(19)$ & 1200 & 216 & 9.5 \\
\cline { 2 - 4 } & $0.9^{b}$ & 1.23 & 0.054 \\
& Anthropogenic dose contribution: & 352.4 & 15.5 \\
\cline { 2 - 4 } & \multicolumn{2}{c}{ NORM dose contribution: } & 15.6 \\
\hline
\end{tabular}

${ }^{a}$ Values are from ICRP Publication 119 [29]

${ }^{b}$ Not measured. The average activity concentration reported by Ref. [13].

In Canada there are two regulatory limits set to help protect the public from anthropogenic radionuclide exposure. Health Canada's "Canadian Guidelines for the Restriction of Radioactively Contaminated Food and Water Following a Nuclear Emergency" [18] provides clear activity concentration action levels for combined ${ }^{134} \mathrm{Cs}$ and ${ }^{137} \mathrm{Cs}$ contamination in commercial food and beverages (1000 $\mathrm{Bq} / \mathrm{kg})$ and in public drinking water $(100 \mathrm{~Bq} / \mathrm{kg})$. The measured radiocesium activity concentrations seen in Table 1 are all less than $0.036 \%$ of the level where action is required to protect the public. To make this point unambiguously clear, Figure 5 provides a graphical representation of the ${ }^{134} \mathrm{Cs}$ and ${ }^{137}$ Cs activity concentrations measured in each Pacific salmon compared with Health Canada's action levels listed above.

The CNSC's effective dose limit for the public from anthropogenic sources is $1 \mathrm{mSv}$ per year. Based on Table 3, we can see that the annual dose for an individual who consumes the average Canadian amount of seafood of $8.8 \mathrm{~kg} /$ year assuming it was all Pacific seafood with the same level of 
Fig. 5. A comparison of the ${ }^{134} \mathrm{Cs}$ (orange) and ${ }^{137} \mathrm{Cs}$ (green) activity concentrations measured in each of the Pacific salmon samples compared with Health Canada's actions levels defined in "Canadian Guidelines for the Restriction of Radioactively Contaminated Food and Water Following a Nuclear Emergency" [18]. In the case where ${ }^{134} \mathrm{Cs}$ or ${ }^{137} \mathrm{Cs}$ were not detected in a given sample, the MDL is shown as an error bar.

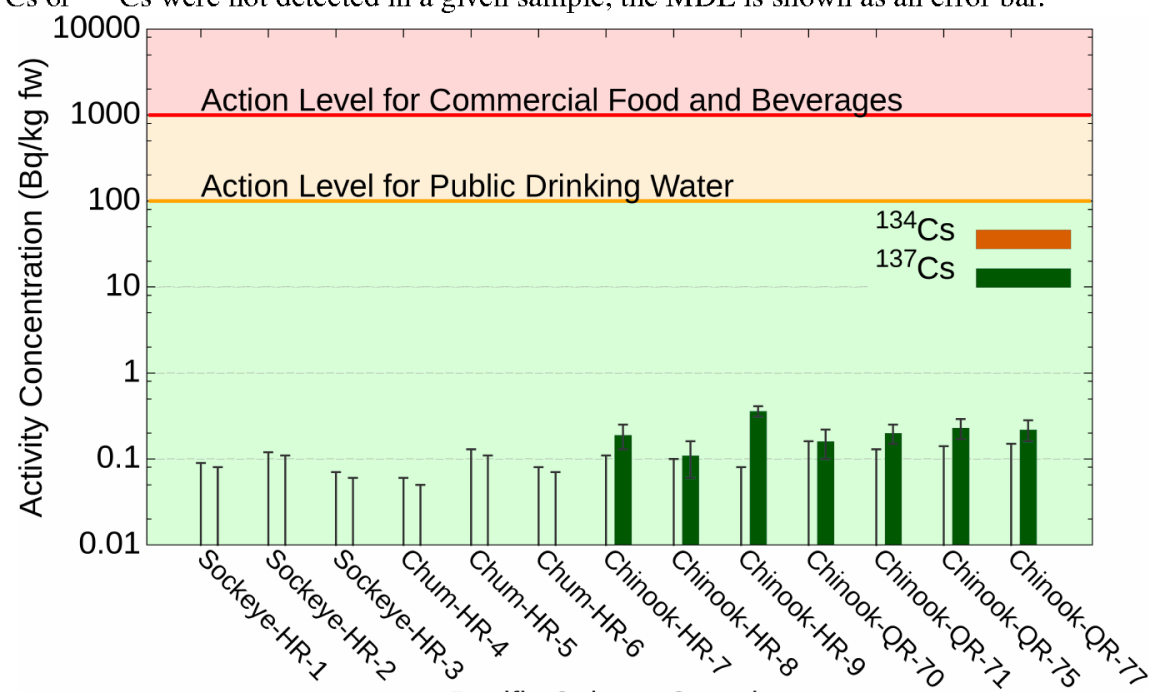

Pacific Salmon Samples

contamination as sample "Chinook-HR-9" would be at most, $5.4 \times 10^{-5} \mathrm{mSv}$ per year. For an individual to reach the CNSC's effective dose limit, they would have to consume at least $162,000 \mathrm{~kg}$ of contaminated seafood per year. As this is an impossible task, we conclude that there is no measurable health risk to the public from consuming anthropogenic radiocesium in contaminated Pacific salmon collected in British Columbia.

The second objective of the monitoring campaigns was to provide a record of anthropogenic contamination in Pacific salmon and soil samples collected in BC. One remarkable observation while viewing Table 1 or Figure 5 is that seven salmon samples which had measurable quantities of ${ }^{137} \mathrm{Cs}$ in them were all Chinook samples. The weighted mean of the activity concentration of ${ }^{137} \mathrm{Cs}$ in the Chinook salmon collected in 2013 from Harrison River, Kilby Provincial Park, BC and the Chinook salmon collected in 2014 from Quesnel River by Likely, BC was $0.23(3)$ and $0.20(3) \mathrm{Bq} / \mathrm{kg}$ fw respectively. These values fall within the ${ }^{137} \mathrm{Cs}$ fw activity concentration range in sockeye salmon measured by Ref. [15] $(0.05-0.28 \mathrm{~Bq} / \mathrm{kg} \mathrm{fw})$ assuming $80 \%$ moisture in each of their samples before freeze-drying. However, in contrast to Ref. [15], no radiocesium was detected in any of the sockeye or chum salmon. While this is an interesting observation, as we would expect to detect at least ${ }^{137} \mathrm{Cs}$ originating from past nuclear weapons tests or the Chernobyl Nuclear Accident, we are unable to pursue this investigation further 
due to our small sample size $(\mathrm{n}=3)$ in both sockeye and chum samples collected. A future measurement campaign of salmon collected from Kilby Provincial Park, BC would be interesting to investigate potential reasons why there was no ${ }^{137} \mathrm{Cs}$ detected in any of the sockeye or chum salmon collected there. Potential reasons for differences in ${ }^{137} \mathrm{Cs}$ concentrations between Pacific salmon species may be as a result of varied diets, differing migration paths into the Pacific Ocean, differences in trophic position, or simply due to random chance. Continued speculation will not be discussed further as a) these questions are unanswerable with the current set of data alone and b) the initial objectives of the monitoring campaign were to simply measure and provide a record of Fukushima-derived contamination if it was present in any of the samples collected.

Fig. 6. A comparison of the ${ }^{134} \mathrm{Cs}$ (orange) and ${ }^{137} \mathrm{Cs}$ (green) activity concentrations measured in each of the soil and roof-debris samples. Despite these samples not being food items, the measured activity concentrations are plotted with Health Canada's actions levels defined in "Canadian Guidelines for the Restriction of Radioactively Contaminated Food and Water Following a Nuclear Emergency" [18] for commercial food and beverages as well as for public drinking water to provide a reference for the eye while comparing the values with the Pacific salmon measurements seen in Figure 5. In the case where ${ }^{134} \mathrm{Cs}$ or ${ }^{137} \mathrm{Cs}$ were not detected in a given sample, the MDL is shown as an error bar.

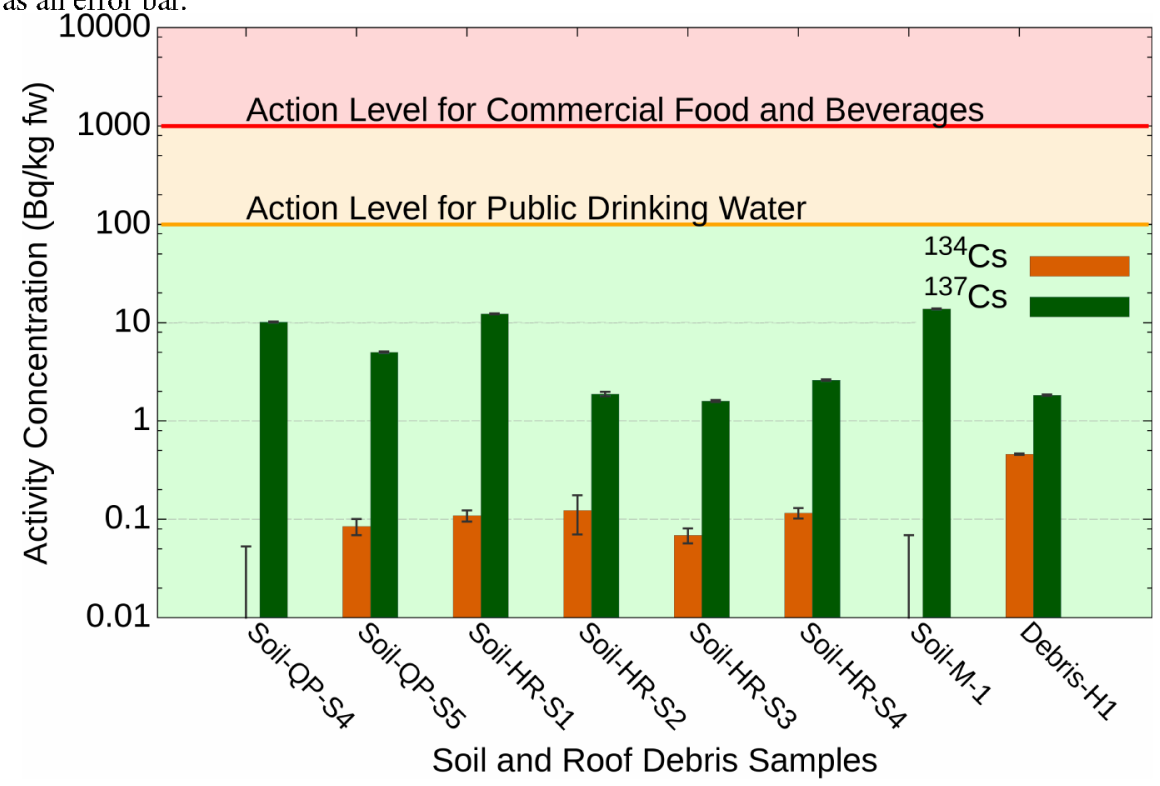

As seen in Table 2, which is represented graphically in Figure $6,{ }^{134} \mathrm{Cs}$ was detected in six of the eight collected soil/roof-debris samples indicating unambiguous Fukushima-derived contamination in these samples. As each of the soil and roof-debris samples was collected inland, we assume that the measured contamination arrived via atmospheric deposition. Evidence which justifies this assumption 
is the detection of ${ }^{7} \mathrm{Be}$, a NORM isotope formed in the atmosphere before depositing on the earth's surface, in all of the soil/debris samples. The two soil samples which did not have detectable quantities of ${ }^{134} \mathrm{Cs}$ had the lowest levels of ${ }^{7} \mathrm{Be}$ detected while each of the other samples collected had relatively higher levels of ${ }^{7} \mathrm{Be}$. While this observation encourages the use of ${ }^{7} \mathrm{Be}$ as a tracer to predict where atmospheric radionuclide contaminants or atmospheric particles in general may deposit on the earth's surface, there are too many variables which are poorly understood [30, 31] to do any meaningful quantitative analysis or address potential correlations between measured ${ }^{134} \mathrm{Cs}$ and ${ }^{7} \mathrm{Be}$ activity concentrations in each sample.

The measured ${ }^{137} \mathrm{Cs}$ activity concentrations in Table 2 and Figure 6 show a huge variation of values, from 1.60 to $13.80 \mathrm{~Bq} / \mathrm{kg}$ fw. As the ${ }^{134} \mathrm{Cs} /{ }^{137} \mathrm{Cs}$ activity ratio in the Fukushima Dai-ichi discharge channels following the release of fission fragments was measured to be 0.99(3) [1] we can designate how much of the ${ }^{137} \mathrm{Cs}$ measured in each sample originated from Fukushima and how much was already present as a legacy of nuclear weapons testing and the Chernobyl Nuclear Accident. In the soil samples which measured ${ }^{134} \mathrm{Cs}$, assuming releases from the Fukushima Dai-ichi reactors began on March 11, 2011, the contribution of ${ }^{137}$ Cs originating from Fukushima ranged from 0.18-0.33 $\mathrm{Bq} / \mathrm{kg}$ fw corresponding to $2.4-17.3 \%$ of the measured ${ }^{137} \mathrm{Cs}$. Compared to the range of ${ }^{137} \mathrm{Cs}$ which did not originate from Fukushima in the soil samples, $1.42-13.65 \mathrm{~Bq} / \mathrm{kg} \mathrm{fw}$, we estimate there to be little impact from Fukushima-derived radiocesium in the soil. In the one roof-debris sample however, the Fukushima-derived ${ }^{137} \mathrm{Cs}$ contribution was calculated to be $1.28(5) \mathrm{Bq} / \mathrm{kg}$ fw indicating that the majority, 70(3)\%, of the ${ }^{137} \mathrm{Cs}$ measured originated from Fukushima. While this is an interesting and unanticipated observation, we do not have an adequate sample size $(n=1)$ to investigate this further.

We conclude that despite there being greater activity concentrations of radiocesium in the soil and roof-debris samples than in the Pacific salmon samples, the measured activities are well below the Canadian action levels for radiocesium contamination in commercial food and beverages (1000 Bq/kg fw) and in public drinking water (100 Bq/kg fw) [18] indicating little risk to no health risks for residents of British Columbia.

\section{Acknowledgement}

This work was supported by the Natural Sciences and Engineering Research Council of Canada (SAPIN/371656-2010).

The authors would like to thank the work of the many citizen scientists who assisted in the field collection of samples. A special thanks to Dr. Frank Gobas and Dr. Victoria Otton from the Environmental Toxicology Research Group lab in the School of Resource and Environmental Management at 
Simon Fraser University for facilitating access to lab equipment. An additional thank you to David Qu and Alexander Fraser for providing access and training to use the freeze drier in the Department of Biological Sciences at Simon Fraser University.

\section{References}

1. Buesseler, K.; Aoyama, M.; Fukasawa, M. Environmental Science and Technology 2011, 45, 9931-9935.

2. Chester, A.; Starosta, K.; Andreoiu, C.; Ashley, R.; Barton, A.; Brodovitch, J. C.; Brown, M.; Domingo, T.; Janusson, C.; Kucera, H.; Myrtle, K.; Riddell, D.; Scheel, K.; Salomon, A.; Voss, P. Journal of Environmental Radioactivity 2013, 124, 205-213.

3. Herod, M. N.; Suchy, M.; Cornett, R. J.; Kieser, W. E.; Clark, I. D.; Graham, G. Water Resources Research 2015, 51, 9628-9645.

4. Masson, O.; de Vismes Ott, A.; Bourcier, L.; Paulat, P.; Ribeiro, M.; Pichon, J. M.; Sellegri, K.; Gurriaran, R. Atmospheric Research 2015, 151, 45-51.

5. Chen, J.; Zhang, W.; Sadi, B. Journal of Environmental Radioactivity 2015, 144, 175-178.

6. Chen, J.; Rennie, M. D.; Sadi, B.; Zhang, W.; St-amant, N. Journal of Environmental Radioactivity 2016, 153, 222-230.

7. Buesseler, K. O.; Jayne, S. R.; Fisher, N. S.; Rypina, I. I.; Baumann, H.; Baumann, Z.; Breier, C. F.; Douglass, E. M.; George, J.; Macdonald, A. M.; Miyamoto, H.; Nishikawa, J.; Pike, S. M.; Yoshida, S. Proceedings of the National Academy of Sciences 2012, 109, 5984-5988.

8. Povinec, P. P. et al. Biogeosciences 2013, 10, 5481-5496.

9. Inoue, M; Furusawa, Y; Fujimoto, K; Minakawa, M; Kofuji, H; Nagao, S; Yamamoto, M; Hamajima, Y; Yoshida, K; Nakano, Y; Hayakawa, K; Oikawa, S; Misonoo, J; Isoda, Y Journal of Environmental Radioactivity 2013, 126, 176-187.

10. Madigan, D. J.; Baumann, Z.; Fisher, N. S. Proceedings of the National Academy of Sciences 2012, 109, 9483-9486.

11. Fisher, N. S.; Beaugelin-Seiller, K.; Hinton, T. G.; Baumann, Z.; Madigan, D. J.; Garnier-Laplace, J. Proceedings of the National Academy of Sciences of the United States of America 2013, 110, 10670-5.

12. Neville, D. R.; Phillips, A. J.; Brodeur, R. D.; Higley, K. A. Environmental Science and Technology 2014, 48, 4739-4743. 
13. Chen, J.; Cooke, M. W.; Mercier, J.-F.; Ahier, B.; Trudel, M.; Workman, G.; Wyeth, M.; Brown, R. Radiation Protection Dosimetry 2014, 1-6.

14. Health Canada Health Canada Analyses of the Radioactive Content of Fish Samples from Canada's West Coast., http: //open . canada . ca/data/en/dataset/d1b39de7-e525-4cfa-a605af38bf 174555, 2016.

15. Domingo, T.; Starosta, K.; Chester, A.; Williams, J.; Ross, P. Radiation Physics and Chemistry in press 2016, DOI: https : //doi .org/10.1016/j.radphyschem. 2016.12.012.

16. Alava, J. J.; Gobas, F. A. P. C. Science of the Total Environment 2016, 544, 56-67.

17. Lin, W.; Chen, L; Yu, W; Ma, H; Zeng, Z.; Lin, J; Zeng, S Atmospheric Environment 2015, 102, $311-322$.

18. Health Canada Canadian Guidelines for the Restriction of Radioactively Contaminated Food and Water Following a Nuclear Emergency: Guidelines and Rationale; tech. rep.; Health Canada, 2000 .

19. Canadian Nuclear Safety Commission Radiation doses - Canadian Nuclear Safety Commission., 2015.

20. deBruyn, A. M. H.; Ikonomou, M. G.; Gobas, F. A. P. C. Environmental Science \& Technology 2004, 38, PMID: 15597874, 6217-6224.

21. Krümmel, E.; Macdonald, R.; Kimpe1, L.; Gregory-Eaves, I; Demers, M.; Smol, J.; Finney, B; Blais, J. Nature 2003, 425, 255-256.

22. Rizwan, U.; Chester, A.; Domingo, T.; Starosta, K.; Williams, J.; Voss, P. Nuclear Instruments and Methods in Physics Research, Section A: Accelerators, Spectrometers, Detectors and Associated Equipment 2015, 802, 102-112A.

23. Agostinelli, S. et al. Nuclear Instruments and Methods in Physics Research, Section A: Accelerators, Spectrometers, Detectors and Associated Equipment 2003, 506, 250-303.

24. Allison, J. et al. IEEE Transactions on Nuclear Science 2006, 53, 270-278.

25. Radford, D. Notes on the use of gf3 (html)., 2000.

26. Cooper, J. Nuclear Instruments and Methods 1970, 82, 273-277.

27. National Nuclear Data Center Interactive Chart of Nuclides., 2017.

28. Fisheries and Oceans Canada Commercial Fisheries - Consumption., 2013. 
29. ICRP Compendium of dose coefficients based on ICRP Publication 60; tech. rep.; ICRP Publication 119, 2012.

30. Caillet, S; Arpagaus, P; Monna, F; Dominik, J Journal of Environmental Radioactivity 2001, 53, 241-256.

31. Jiwen, L.; Starovoitova, V. N.; Wells, D. P. Journal of Environmental Radioactivity 2013, 116, $42-47$. 